\title{
Effects of Opium Addiction on Level of Sensory Block in Spinal Anesthesia With Bupivacaine for Lower Abdomen and Limb Surgery: a Case-Control Study
}

\author{
Seyyed Hasan Karbasy ${ }^{1}$; Pooya Derakhshan ${ }^{1, *}$ \\ ${ }^{1}$ Birjand University of Medical Sciences, Birjand, Iran \\ *Corresponding author: Pooya Derakhshan, Birjand University of Medical Sciences, Birjand, Iran. Tel: +98-9123884643, E-mail: pooyaderakh@yahoo.com
}

Received: August 2, 2014; Revised: October 22, 2014; Accepted: November 8, 2014

\begin{abstract}
Background: In clinical practice, the level of sensory block in spinal anesthesia in opium abusers is lower than that in non-abusers because of adaptive changes caused by opium use.

Objectives: The aim of this study was to investigate the level of sensory block resulting from the intrathecal administration of $0.5 \%$ bupivacaine in opium abuser patients undergoing lower extremity and lower abdominal surgeries.

Patients and Methods: A total of 100 patients who were candidates of elective lower extremity orthopedic and lower abdominal surgeries were recruited and assigned to two groups based on their history of opium addiction (Case or control). Both groups underwent the same anesthesia procedure and pinprick test was used to assess the level of anesthesia.

Results: No statistically significant difference was observed between groups regarding age, duration of the surgery, and type of surgery. The frequency of addiction was higher in males than in females. The level of sensory block at three minutes was significantly lower in the opium abuser group $(\mathrm{P}=0.006)$. The mean time to achieve $\mathrm{T10}$ sensory block was $10.33 \pm 5.79$ minutes in the opium abusers and $6.89 \pm 3.88$ minutes in the controls $(\mathrm{P}=0.001)$. The level of the highest sensory block was lower in the opium abuser group $(\mathrm{P}=0.002)$.

Conclusions:The findings of this study suggested that after induction of spinal anesthesia with intrathecal administration of bupivacaine, chronic opium abusers would have a lower level of sensory block in comparison with patients without a history of opium abuse.
\end{abstract}

Keywords:Opium; Addiction; Spinal Anesthesia

\section{Background}

The opioid analgesics are frequently used for severe acute and chronic pain states (1). Prolonged use of opioids results in analgesic tolerance, which is the progressive need for higher doses to attain a steady analgesic effect. The exact mechanisms that cause this phenomenon remain unclear (1-3); however, several proposed hypotheses concern the action of opioid receptors and endogenous opioid peptides (1-4). Moreover, more findings regarding pain and its regulation in opium abusers have been emerged recently (5-8). These findings consist of a crossinteraction and cross-tolerance between local anesthetics and opioids at the receptor level of the spinal cord. In the clinicstime of spinal anesthesiain opium abusers is shorter resulting in a need for supplemental analgesics and sedatives during the operations $(1,5)$.

In clinical practice, the level of sensory block in spinal anesthesia in opium abusers is lower than that in nonabusers. This clinical occurrence could be related to a number of previously observed conditions linked to opioid tolerance such as a change in spinal neuronal activity and its associated mediators, the neuronal cellular channels, and receptors due tofrequent exposure to opi- oids (1-3, 8-11). These findings show that the neuroplastic changes caused by opioid exposure encourage increased pain transmission, which results in a reduced antinociception known as clinical opioid tolerance(1-3). In addition, opioids could affect several adaptive mechanisms in the pain system that provokes amplified pain sensation because of facilitation in descending, up-regulation of spinal dynorphins, and improved release of excitatory transmitters from primary afferents in response to the constant and repetitive exposure to opioids. Considering these adaptive change, the need for a better assessment of the clinical consequences of long-term opioid use becomes prominent (1).

\section{Objectives}

The aim of this study was to compare the level of sensory block of intrathecal administration of $0.5 \%$ bupivacaine between opium abuser and non-abuser patients undergoing lower extremity and lower abdominal operations.

\section{Patients and Methods}

This study conformed to the criteria of the Ethics Committee, Department of Research Affairs, Faculty of Medi- 
cine, Birjand University of Medical Sciences, Birjand, Iran. Informed consent was obtained from all subjects before participating in the trial. In this descriptive-analytical case-control study, the study population was defined as all the patients who had surgical operations at Emam Reza hospital during a six-month period. A total of 100 patients aged 18 to 70 years, who were candidates for elective lower extremity orthopedic and lower abdominal surgery and all were classified as American Society of Anesthesiologists (ASA) category I or II, were recruited.

The patients were assigned to two groups based on history of opium use. The case group had a history of chronic opium abuse (through respiratory or gastrointestinal routes) for at least one year with a history of withdrawal syndrome as a result of any cessation during opium usage. In addition, all opium users reported to use a daily dose of 1 to $2 \mathrm{~g}$ of opium per day. The control group had no self-reported history of opium use for the last two years. Moreover, patients with a history of any other substance abuse, a history of cardiac, pulmonary, or kidney diseases, coagulopathy or thrombocytopenia, a history of infection in site of needle puncture, and those who did not accept subarachnoid block were excluded.

A routine physical examination and visit were performed for all of the participants the night before the surgery by the same anesthesiologist and the patients were informed about the study objectives and their treatment process once again. It was recommended to the patients in the case group to use their usual daily dose of opium at the night before surgery and their used dose and method of usage were documented. All the patients were nil peros (NPO) for eight hours before the scheduled operation time. Following the start of standard monitoring (electrocardiography, pulse oximetry, noninvasive blood pressure, and heart rate monitoring), the patients received $500 \mathrm{~mL}$ of Ringer's solution over 10 to 15 minutes. Subarachnoid blocks were performed in the sitting position under sterile conditions by the same anesthesiologist. A 25 gauge Whitacre spinal needle was inserted via a midline approach in the L3- L4 interspace. The needle bevel was oriented cephalad while $15 \mathrm{mg}$ ( $3 \mathrm{~mL}$ ) of $0.5 \%$ preservative-free hyperbaric bupivacaine was injected at a rate of $1 \mathrm{~mL}$ every five seconds. The patient's position was changed to neutral supine after drug injection.

The level of anesthesia was checked every ten seconds for the ten minute through the pinprick test by different anesthesiologists blinded to the patients' status. Then, the level of anesthesia was checked and documented every five minutes from the minute 10 to minute 180 of subarachnoid drug administration. If patient had any pain at any time during the operation, the anesthesia method would be changed to general anesthesia without any additional intravenous analgesics. The level of sensory block at minute three was recorded and the time to achieve T10 sensory block was recorded (using a pinprick test) and documented from the time of drug injection. Moreover, from the minute 10 to minute 180 , he patients were checked every five minutes to detect and document the level of sensory block as well as the level of the highest sensory block.

All analyses were performed using Student's test and where appropriate, by Chi square test. P value $<0.05$ was considered statistically significant. Data entry and analysis were performed by SPSS 11.5 (SPSS Inc., Chicago, IL, USA).

\section{Results}

The study groups had no statistically significant differences regarding age, duration of the surgery, and type of surgery. The frequency of addiction was higher in males than in females (Table 1). The mean duration of opium abuse in the cases group was $2.0 \pm 5.5$ years and the mean daily opium use was $1.5 \pm 1.5 \mathrm{~g}$. The most common pattern of abuse was inhalation (56\%, 28 patients) and the remaining 22 patients (44\%) abused opium orally.

The level of sensory block at three minutes was significantly lower in the abuser group in comparison to controls $(\mathrm{P}=0.006)$ (Table 2$)$. The mean time to achieve T10 sensory block was $10.33 \pm 5.79$ minutes in the abusers and $6.89 \pm 3.88$ minutes in controls $(\mathrm{P}=0.001)$. The level of the highest sensory block was lower in the abuser group in comparison to controls ( $\mathrm{P}=0.002)$ (Table 2 ).

Table 1. Distribution of Age, Body Weight, and Sex in Two Study Groups a

\begin{tabular}{lccl}
\hline & $\begin{array}{c}\text { Chronic opium } \\
\text { Abusers }\end{array}$ & Non-abusers & P value ${ }^{\mathrm{b}}$ \\
\hline Age, $\mathbf{y}$ & $47.46 \pm 16.59$ & $45.92 \pm 22.71$ & $>0.05$ \\
Body Weight, $\mathbf{k g}$ & $63.5 \pm 9.6$ & $62.9 \pm 9.4$ & $>0.05$ \\
Male & 9 & 19 & $<0.05$ \\
Female & 41 & 31 & $<0.05$ \\
\hline $\begin{array}{l}\text { a Data are presented as mean SD or No. } \\
\text { b }\end{array}$ P values were calculated using Student's t test or Chi-square test.
\end{tabular}

Table 2. Distribution of the Level of Sensory Block at the Third Minute and the Highest Level of Sensory Block in Study Group ${ }^{\text {a }}$ Minute and the Highest Level of Sensory Block in Study Group a Chronic
Opium Abusers

\begin{tabular}{|lccc|}
\hline $\begin{array}{l}\text { Sensory Block Level at } \\
\text { the 3rd Minute }\end{array}$ & & & \\
\hline L2 & 21 & 8 & 0.006 \\
\hline T12 & 15 & 13 & - \\
\hline T10 & 8 & 8 & - \\
\hline T8 & 1 & 12 & - \\
\hline T6 & 5 & 9 & - \\
\hline
\end{tabular}

\section{The Highest Level of}

Sensory Block

\begin{tabular}{lccc} 
T10 & 41 & 21 & 0.002 \\
T8 & 5 & 14 & - \\
T6 & 3 & 13 & - \\
T4 & 1 & 2 & - \\
\hline
\end{tabular}

$\mathrm{a}$ Data are presented as No.
$\mathrm{b}$ P values were calculated using Chi-square test. 


\section{Discussion}

Several factors can influence the level of block in spinal anesthesia including the controllable factors such as dose (volume $\times$ concentration), site of injection, neuraxis, baricity of the local anesthetic solution, posture of the patient, and uncontrollable factors such as volume of cerebrospinal fluid and density of cerebrospinal fluid (12-16).

Administration of opioids normally causes analgesia; however, in some circumstances, the opioid receptor system signals and modulates several effects and mediates hyperalgesia rather than analgesia $(4,11,17-21)$. Recent studies suggest that opioid-induced hyperalgesia is a multifactorial phenomenon that involves multiple potential areas of pain amplification including descending tonic facilitation originating in the rostral ventromedial medulla, the release of pronociceptive spinal dynorphin, and the potential interaction of excitatory amino acid neurotransmitters with other receptor systems. The role of these pain facilitating processes in the development of local anesthetic tolerance is unclear. In addition to the known opioid receptors, several other receptors are influenced by opioids in both peripheral and central nervous system (CNS) $(4,11,17-20)$.

In a review of the precise mechanisms resulting in opioid-induced hyperalgesia, it was concluded that opioidergic mechanisms can oppose analgesic mechanisms and therefore, enhance sensitivity to pain (13). The source of such mechanisms has been suggested to be in the afferent neurons, spinal cord tissue, and supraspinal centers of the CNS (21).

Excitatory amino acid neurotransmitters and receptor systems are involved in pain sensitivity augmentation at spinal level (13). Therefore, other possible mechanisms of opioid-induced hyperalgesia could be tonic activation of descending pain facilitation, probably as a result of amplified expression of mediators such as cholecystokinin (1-4), calcitonin gene-related peptide (CGRP1), and substance $P$ in a number of spinal cord segments $(1,22)$ with the presence of pronociceptive neuroplastic changes within the spinal cord neurons (1).

As explained by Dogrul et al. several opioid-induced abnormal pain states exist that are characterized clinically and behaviorally as antinociceptive tolerance; these pain states are not related, clinically or in quality, to the original complaint of pain for which opioid therapy was administered (23).

Vanderah et al. showed that administration of lidocaine in the rostral ventromedial medulla could block opioidinduced pain $(9,10)$. In addition, Allen and Dykstra, and Lai et al. noted that N-methyl D-aspartate (NMDA) receptor antagonists could effectively prevent a process leading to morphine development $(11,24)$. Lai et al. suggested that voltage-gated sodium channels have a significant function in many types of chronic pain (24). Considering the results of mentioned studies, in view of the down- regulation of the opioid receptors and their connected intracellular systems in chronic opium abusers $(21,24)$, a synchronized drug tolerance to the effects of local anesthetics in the spinal cord during intrathecal administration of these drugs might be a probable mechanism for shorter time of block in opium abusers in our study. This tolerance, which is a cross-tolerance mechanism in the spinal cord, is a frequent finding for several other pharmaceutical products (4).

Poorer effectiveness of the intrathecal local anesthetics might be due to lower than normal thresholds of the neurons for pain sensitization and probable neuroplastic changes in pain receptors of spinal cord. In addition to the usual opioid receptors, a number of animal studies have named several other receptors influenced by opioids in both the CNS and the peripheral nervous system (4-7, 21, 25). Moreover, various structural similarities between opioid and local anesthetic receptors in the spinal cord have been suggested $(6,25)$. Interestingly, new drugs that simultaneously affect both the opioid and local anesthetic drug receptors in the spinal cord are introduced (6, 21-26). The structural and/or functional similarities between opioid and local anesthetic receptors at the spinal cord level could fairly explain that in chronic opium abusers, reduced tolerance to opium compounds concurrently creates a condition of tolerance. More studies are needed to explore the transduction and processing mechanisms of pain in the CNS and to explain the reasons of reduced duration of local anesthetic drugs block after intrathecal administration (21).

Our study had some limitations. Firstly the exact dose of opium use of the case group could not be documented. Secondly, due to legal issues, it was not possible to provide all patients with the same kind of opium.

In Conclusion, after induction of spinal anesthesia with intrathecal administration of bupivacaine, a lower level of sensory block was observed in chronic opium abusers in comparison to controls. Hence, these patients should be handled in a way to elevate the block level of anesthesia and analgesia, by either adding intrathecal opioid adjuvants to the local anesthetic solution or using a higher dose of local anesthetics to enhance the sensory block level.

\section{Authors' Contributions}

Seyyed Hasan Karbasi participated in the study concept and design. Pooya Derakhshanperformed analysis and interpretation of data, drafting the manuscript, revision of the manuscript for important intellectual content, and statistical analysis.

\section{Funding/Support}

The funding organizations were public institutions and had no role in the design and conduct of the study, collection, management, and analysis of the data, or preparation, review, and approval of the manuscript. 


\section{References}

1. Ossipov MH, Lai J, King T, Vanderah TW, Porreca F. Underlying mechanisms of pronociceptive consequences of prolonged morphine exposure. Biopolymers. 2005;80(2-3):319-24.

2. Gardell LR, King T, Ossipov MH, Rice KC, Lai J, Vanderah TW, et al. Opioid receptor-mediated hyperalgesia and antinociceptive tolerance induced by sustained opiate delivery. Neurosci Lett. 2006;396(1):44-9.

3. Ossipov MH, Lai J, King T, Vanderah TW, Malan TP, Jr., Hruby VJ, et al. Antinociceptive and nociceptive actions of opioids. J Neurobiol. 2004;61(1):126-48.

4. Szeto HH, Soong Y, Wu D, Qian X, Zhao GM. Endogenous opioid peptides contribute to antinociceptive potency of intrathecal [Dmt1]DALDA. J Pharmacol Exp Ther. 2003;305(2):696-702.

5. Chen SR, Pan HL. Antinociceptive effect of morphine, but not mu opioid receptor number, is attenuated in the spinal cord of diabetic rats. Anesthesiology. 2003;99(1409-14).

6. Marchand F, Ardid D, Chapuy E, Alloui A, Jourdan D, Eschalier A. Evidence for an involvement of supraspinal delta- and spinal mu-opioid receptors in the antihyperalgesic effect of chronically administered clomipramine in mononeuropathic rats. J Pharmacol Exp Ther. 2003;307(1):268-74.

7. Hurley RW, Banfor P, Hammond DL. Spinal pharmacology of antinociception produced by microinjection of mu or delta opioid receptor agonists in the ventromedial medulla of the rat. Neuroscience. 2003;118(3):789-96.

8. Yoburn BC, Gomes BA, Rajashekara V, Patel C, Patel M. Role of G(i)alpha2-protein in opioid tolerance and mu-opioid receptor downregulation in vivo. Synapse. 2003;47(2):109-16.

9. Vanderah TW, Suenaga NM, Ossipov MH, Malan TP, Jr., Lai J, Porreca F. Tonic descending facilitation from the rostral ventromedial medulla mediates opioid-induced abnormal pain and antinociceptive tolerance. J Neurosci. 2001;21(1):279-86.

10. Xie JY, Herman DS, Stiller CO, Gardell LR, Ossipov MH, Lai J, et al. Cholecystokinin in the rostral ventromedial medulla mediates opioid-induced hyperalgesia and antinociceptive tolerance. $J$ Neurosci. 2005;25(2):409-16.

11. Allen RM, Dykstra LA. The competitive NMDA receptor antagonist LY235959 modulates the progression of morphine tolerance in rats. Psychopharmacology (Berl). 1999;142(2):209-14.

12. Greene NM. Distribution of local anesthetic solutions within the subarachnoid space. Reg Anesth Pain Med.1998;23:347.
13. Hocking G, Wildsmith JA. Intrathecal drug spread. Br J Anaesth. 2004;93(4):568-78

14. Pitkanen M, Haapaniemi L, Tuominen M, Rosenberg PH. Influence of age on spinal anaesthesia with isobaric $0.5 \%$ bupivacaine. Br J Anaesth. 1984;56(3):279-84.

15. Holman SJ, Robinson RA, Beardsley D, Stewart SF, Klein L, Stevens RA. Hyperbaric dye solution distribution characteristics after pencil-point needle injection in a spinal cord model. Anesthesiology. 1997;86(4):966-73.

16. Urmey WF, Stanton J, Bassin P, Sharrock NE. The direction of the Whitacre needle aperture affects the extent and duration of isobaric spinal anesthesia. Anesth Analg. 1997;84(2):337-41.

17. Angst MS, Clark JD. Opioid-induced hyperalgesia: a qualitative systematic review. Anesthesiology . 2006;104:570-87.

18. Christie MJ, Williams JT, North RA. Cellular mechanisms of opioid tolerance: studies in single brain neurons. Mol Pharmacol. 1987;32(5):633-8.

19. Bovill JG. Mechanisms of actions of opioids and non-steroidal anti-inflammatory drugs. EurJ Anaesthesiol Suppl. 1997;15:9-15.

20. Wu HE, Thompson J, Sun HS, Leitermann RJ, Fujimoto JM, Tseng LF. Nonopioidergic mechanism mediating morphine-induced antianalgesia in the mouse spinal cord. J Pharmacol Exp Ther. 2004;310(1):240-6.

21. Angst MS, Clark JD. Opioid-induced hyperalgesia: a qualitative systematic review. Anesthesiology. 2006;104(3):570-87.

22. King T, Gardell LR, Wang R, Vardanyan A, Ossipov MH, Malan TP, Jr., et al. Role of NK-1 neurotransmission in opioid-induced hyperalgesia. Pain. 2005;116(3):276-88.

23. Dogrul A, Bilsky EJ, Ossipov MH, Lai J, Porreca F. Spinal L-type calcium channel blockade abolishes opioid-induced sensory hypersensitivity and antinociceptive tolerance. Anesth Analg. 2005;101(6):1730-5.

24. Lai J, Porreca F, Hunter JC, Gold MS. Voltage-gated sodium channels and hyperalgesia. Annu Rev Pharmacol Toxicol. 2004;44:37197.

25. Hurley RW, Banfor P, Hammond DL. Spinal pharmacology of anti nociception produced by microinjection of mu- or delta-opioid receptor agonists in the ventromedial medulla of the rat. Neuroscience. 2003;118:789-96.

26. Modalen AO, Westman L, Arlander E, Eriksson LI, Lindahl SG. Hypercarbic and hypoxic ventilatory responses after intrathecal administration of bupivacaine and sameridine. Anesth Analg. 2003;96(2):570-5. 